\section{La descodificación y fractura del Derecho Civil}

Publicado no La Ley ano LVIII no 153 de 11 de agosto de 1994. Buenos Aires, República Argentina.

\section{Ricardo Luis Lorenzetti}

SÚMARIO:

I. Introducción; II. El surgimiento de los microsistemas; III. Crisis de la noción jurídica de pueblo y de ciudadano; IV. El jurista del microsistema; V. El desprestigio de la ley; VI. La crisis de la parte general del Derecho Civil; VII. La crisis cultural del Derecho Civil; VIII. Competência legislativa en mercados integrados. - IX. La fractrura del Derecho Civil.

\section{Introducción}

1. Recopilaciones de leyes y codificación: cuál es la situación actual?

Antes de los Códigos había recopi-laciones. Estas pretendían reproducir el derecho existente, sin modificarlo: sólo continuarlo, mejorarlo, en un continuun histórico. Las obras legislativas totalizadoras eran recopilaciones, como las de Indias; o una selección de textos escogidos, como los Digestos; o un espejo de lo existente, como el Swabspiegel.

En cambio, el Código no es continuidad; es una ruptura. Pretende crear una nueva regulación, sustitutiva; no recopila, sino que ordena basándose en la racionalidad ${ }^{1}$. Tiene un carácter constituyente del derecho privado.

La recopilación generaba inseguridad porque no se sabía si tal o cual disposición estaba vigente. El Código es seguridad, se traduce en una secuencia ordenada de artículos. La inmutabilidad es una de las características esenciales; no se puede alterar una parte sin cambiar el todo.

La legislación anterior era incognoscible por el ciudadano. El Código, se diseñó como una suerte de manual de derecho porque, como decía Andrés Bello, "podrá andar entonces en manos de todos, podrá ser consultado por cada ciudadano en los casos dudosos y servirle de guía en el desempeño de sus obligaciones"2.
En la recopilación no había axiomas fundantes; los principios debían rastrearse en la maraña legislativa. En cambio, en el Código, el modelo es deductivo3. El Código genera una ciencia demostrativa, cuyo propósito es hacer evidentes los axiomas; en la descodificación en cambio, había que indagar los hechos jurídicos para encontrar los principios.

En la recopilación, el intérprete tenía una enorme tarea y era gran protagonista. El Código, en cambio, recorta el espacio de la interpretación jurídica, la cual se limita exclusivamente a la ley y deviene en exégesis.

El Derecho Civil codificado, es autosuficiente, no necesita de otros textos para solucionar las disputas. Al tener una parte general ordenada, exporta instituciones y técnicas. Así sucede por ejemplo, con el negocio jurídico que se pretende aplicable al derecho de familia, al administrativo, al laboral ${ }^{4}$.

En cambio, la recopilación es insular, está alejada de los continentes. Al contrario del Código, importa conocimientos y situaciones de otros territorios, também insulares. Su caráter casi portuario le permite recibir contactos con la economía, la medicina, el arte de la guer$\mathrm{ra}$, la tecnología, incorporando sus intereses, reglas y lenguajes.

Señaladas estas breves diferencias, cabe preguntarnos: Cuál es la situación actual?
Todos diríamos que tenemos un Código ril, y por tanto un derecho codificado. Pero ıbién podríamos asumir aquella afirmación rrincipios del siglo XIX, que hiciera el Conde Carrabús: he recorrido "con espanto sella mole inmensa e incoherente de cracia, republicanismo, despotismo militar, arquía feudal, de errores antiguos y ravagancias modernas, aquella mole de inta y seis mil leyes con sus formidables nentadores" 5 .

Ya superamos las treinta y seis mil leyes; el dadano las desconoce; el Código pierde arcabilidad, la legislación especial es ogatoria de los principios generales codifilos. Es dificil establecer un orden, y más aún ntener principios axiomáticos.

La tarea del intérprete se ha vuelto decisiprueba de ello es el rol protagónico que se reconoce al juez, y la labor creativa de la isprudencia y doctrina. El lenguaje jurídico ha contaminado de genética, economía, ral, tecnología, computación, y ese poco exporta al resto de la sociedad.

Asistimos a una era de descodificación? aminaremos este problema con un criterio plio, no reducido a la dogmática o a los iflictos intralegislativos ${ }^{6}$, para presentear el iómeno en su globalidad. No sólo hay una icodificación legislativa, sino un problema explosión con una enorme fuerza centrípeta, sintegradora, en el plano de la ley, de otras intes, de la doctrina, y del derecho privado general.

Nos parece necesario este enfoque amplio ra luego, en una segunda parte, advertir el lómeno contrario y arribar a nuestra tesis asiste a una progresiva recodicación constiional del derecho privado.

\section{El big bang legislativo}

El Código fue un reflejo de la creación del tado nacional; su pretensión era ordenar las nductas jurídico-privadas de los ciudadanos, forma igualitaria; una sola norma aplicable para todos los ciudadanos por igual, sean ciudadanos o extranjeros (art. 1, Cód. Civil Argentino).

El Código significó una garantía de separación entre la sociedad civil y el Estado. Con anterioridad, si una cuestión no podía resolverse por las leyes civiles, se remitía al soberano; ahora en cambio se resuelve mediante leyes análogas o principios generales de derecho (art. 16 y nota, Cód. Civil Argentino).

Finalmente, el Código es un orden racional que se propone regular en todos los tiempos y latitudes.

El Derecho Civil actual no se basa en una sola ley codificada; por el contrario hay muchas leyes para distintos sectores de actividades y ciudadanos.

$\mathrm{La}$ igualdad legislativa es un sueño olvidado, en la medida en que las normas juridicas son particularizadas y con efectos distributivos precisos.

La idea de ordenar la sociedad ha perimido al ritmo del decaimiento de las visiones totalizadoras; el derecho civil se presenta como una estructura defensiva del ciudadano y de colectividades antes que como el "orden" social.

El Código comparte su vida con otros Códigos, com microsistemas jurídicos, y con subsistemas. El Código ha perdido centralidad, la que desplaza progresivamente ${ }^{7}$. El Código es sustituido por la constitucionalización del Derecho civil, y el orden codificado por el sistema de derecho civil, que abarca tanto a la norma codificada como a otras.

La explosión del Código produjo un fraccionamiento del orden, similar al planetario. Se han creado microsistemas jurídicos, que al igual que los planetas giran con su propia autonomía, su vida es singular; el Código es como el sol, los ilumina, colabora en su vida, pero ya no puede incidir directamente sobre ellos.

También se puede usar la famosa descripción que empleara Wittgenstein ${ }^{8}$, aplica- 
da al Derecho, puesto que el Código es el viejo centro de la ciudad, a la que se le han añadido nuevos suburbios, con sus propios centros, $y$ características barriales. Poco es lo que se visitan unos y otros; al centro se va de vez en cuando a contemplar las reliquias históricas.

\section{El surgimento de los microsistemas}

Se ha producido una inversión de la ley de Maine, quien señalaba que la tendencia de la civilización es evolucionar desde el estatus al contrato; ahora se evoluciona del contrato al derecho estatutario. nos.

Veremos seguidamente algunos fenóme-

\section{El microsistema de la empresa}

Sin demasiado asombro hemos asistido a la desintegración del Código de Comercio decimonómico; basta mencionar las leyes: quiebras (ley 19.551 -Adla, XIIV-D, 3806-), sociedades (19.550 -Adla, XLIV-B, 1310-), navegación (20.094 -Adla, XXXIII-A, 170-), patentes (111 -Adla, 1852-1880, 432-), cooperativas (20.337 -Adla, XXXIII-b, 1506-), transferencia de tecnología (22.426-Adla, XII$\mathrm{A}, 210$-), inversiones estranjeras (21.382-Adla, XXXVI-C, 2071-), competencia (22.262-Adla, XL-C. 2521-), abastecimiento (20.680 -Adla, XXXIV-C, 2006), lealtad comercial (22.802 XIIII-B, 1346-), títulos valores (decs. 5965 y 4776), contrato de seguro (17.418 -Adla, XXXVII-B, 1677-), empresas de seguros (20.091 -Adla, XXXIII, 150-), actividades financieras (21.526 -Adla, XXXVII-A, 121-), bolsas (ley 17.811 -Adla, XXVIII-B, 1979- y modif.), martilleros (20.266 -Adla, XXXIII-B. 1384-), productores y asesores de seguros (22.400Adla, XII-A, 161-), compraventa internacional (Convención de Viena de 1980), instrumentos de medición (Ley 19.551 -Adla, XXXIIIA, 1725-); Casas de cambio (Ley 18.924-Adla, XXXI-A, 92-); transferencia de fondos de comercio (11.867 -Adla, 1920-1940, 524-), y otras muchas.
La materia más importante está regulada poe leyes especiales, que no son aplicaciones particularizadas de la norma general que se encuentra en el Código de Comercio, sino verdaderos estatutos especiales.

Por otra parte, quien es especialista en "derecho bancario", seguramente se abstendrá de opinar sobre derecho de la navegación o aduanero o impositivo. Cada especialidad va adquiriendo su propia dificuldad, y es dificil hablar de un derecho comercial totalizador.

Además tiene sus propias fuentes de creación normativa. La costumbre internacional es determinante a la hora de la redacción de los tratados', y a través de ellos penetra en los derechos internos provocando fricciones "culturales" 10. También la costumbre se impone a través de la propia actividad trasnacional: un ejemplo de ello es cómo la actividad reaseguradora internacional, impone cláusulas a las aseguradoras nacionales y éstas a los consumidores internos.

También en el Derecho procesal se gana en autonomía. Las controversias interempresarias se resuelven cada vez menos en la justicia ordinaria, y cada vez más mediante soluciones alternativas. Tales son el arbitraje o los contratos "inmunizados", o las garantias a primera demanda o autoliquidables ${ }^{11}$.

El Derecho Comercial tiene sus propios principios, sus doctrinarios y congresos.

El Derecho Comercial sufre además de un defecto de origen. Fue pensado como un subsidio a la clase comerciante mediante normas flexibilizadoras y prescindiendo de toda consideración de la otra parte: el consumidor.

El movimiento consumerista, desde los años 70 , viene modificando la legislación comercial mediante la introducción de instituciones de todo tipo que afectan las disposiciones tradicionales. Así, la venta al público, por correo, a domicílio, la prestación de servicios, se ven modificados sustancialmente.
Estamos en presencia de un verdadero icrosistema de la empresa, que exhibe sus incipios, normas, fuentes de creación, ctrina, jurisprudencia, particularizadas.

\section{Microsistema de protección del}

consumidor

El Derecho Civil codificado regula los conatos subsidiariamente, respetando la tonomía privada, ayudándola mediante el recho supletorio y recortándola a través del den público imperativo. Las nulidades son presas y conducen a la frustración del nego).

El derecho de protección de los consumires ha cambiado todo esto. Ab initio instala $\iota$ orden protectorio que deroga el principio neral de la igualdad de los ciudadanos. El den supletorio se torna imperativo, surgen ; "nulidades virtuales", y pretenden el antenimiento del propósito práctico perseido por los contratantes. Los sistemas de ódulos abiertos para la calificación de cláulas contractuales abusivas, el "listado de cláulas negras y grises", el control administratii previo, el desechamiento de algunas cláusu; manteniendo el negocio y rediseñándolo n poco frecuentes en el derecho común.

El Derecho Civil diseñó el principio de lo ectos relativos de los contratos. El derecho : consumo lo destruyó, al sugerir la iputación por daños al fabricante, al distri iidor, al mayorista, al titular de la marca, que , han celebrado contrato alguno con el conmidor, como ocurre en la ley brasileña 8078 1. Asimismo, se conceden acciones al consuidor, al usuario, a miembros del grupo famiir, a las asociaciones de consumidores, que mpoco han tenido vínculos convencionales evios.

La responsabilidad precontractual por andono intespestivo de las tratativas previas zne por objeto evitar el retiro incausado bitrario, dañoso. Esta concepción del derecho vil es modificada en el derecho de consumo facilitarse el retiro rápido, intenpestivo del consumidor en las ventas a domicilio como sucede en la ley argentina 24.240 (Adla, LIII$\mathrm{D}, 4125)$.

Como se ve con estos breves ejemplos, el derecho del consumo diseña sus propios principios, diferentes de los que sirven de arquitectura al derecho común.

En Brasil, se ha considerado a nivel constitucional que el derecho del consumo debe tener su "Código", dictándose la ley 8078 que es un Código de defensa del consumidor, lo que permite "coherencia, homogeneidad a una determinada rama del derecho, posibilitando su autonomía"12.

Asimismo puede tener su derecho penal a través de la tipificación de delitos de consumo 13

Es habitual que tenga normas procesales particularizadas, que protegen derechos individuales homogéneos, o difusos, y sus propios tribunales, de menor cuantía o arbitrales ${ }^{14}$.

El derecho de protección de los consumidores tiene sus propios congresos y doctrinarios, altamente especializados en el tema, que se reúnen entre sí desarrollando actividades específicas.

Asimismo, asistimos a una descodificación interna. Hoy se percibe que se parcializa el enfoque en áreas, tales como alimentos, fármacos, vivienda, crédito, etc. Cada una de ellas está regulada por una enorme cantidad de resoluciones ${ }^{15}$, acuerdos, reglamentos, directivas, "instructivos", disposiciones del Ombudsman, de las convenciones colectivas de consumo, de los organismos de contralor. Incluso se advierten hoy enfoques doctrinarios especializados 16

Estamos en presencia de un verdadero microsistema de protección del consumidor, que exibe sus principios, normas, fuentes de cración, doctrina, jurisprudencia, particularizadas.

3. Daños: crisis de la unicidad de lo ilícito

El derecho de daños ha crecido fuera del Código, fundándose en la producción 
jurisprudencial y las leyes especiales. Los escasos artículos que dedica el Código Civil a la responsabilidad civil no explican la explosión de litigios, de obras doctrinarias, de congresos sobre el tema.

Esto ha producido una crisis de la unidad del fenómeno resarcitorio.

Hay coincidencia doctrinaria en que la ilicitud es un fenómeno que responde a una unidad sistemática. En virtud de ello la antijuridicidad, imputabilidad, nexo causal y daño son presupuestos aplicables a los casos que surgen en el ámbito contractual, aquiliano, público o privado. Esta unicidad se refiere a la independencia de la causa fuente del crédito: cualquiera sea la causa se aplican los mismos principios.

Sin embargo, los valores inherentes son distintos y cada vez más parcelados. Si bien todos responden a los principios de la responsabilidad aquiliana, no es lo mismo un accidente de tránsito que la respon-sabilidad precontractual; no es equivalente el daño ecológico que la transmisión de enfermedades de padre a hijo.

Por esta razón, surge el derecho estatutario en la responsabilidad civil: Los accidentes de trabajo (ley 24.028 -Adla, LI-D, 3914), los de minería (Cód. de Minería - Adla, 1881 - 1888, 230-), Código Aeronáutico (17.285 - Adla, XXVII-A, 326-), daños nucleares (Convención de Viena, ley 17.048 -Adla, XXVI-C, 1625-), actos discri-minatorios (ley 23.592 -Adla, XIVIII-D, 4179-), accidentes de tránsito (dec. 692/92 -Adla, LII-B, 1725-), los deportivos (ley 24.192 -Adla, LIII-B, 1340-), resarcimiento los detenidos durante el proceso militar 24.043 -Adla, LII-A, 30-). Pero además, por la vía jurisprudencial se crean normas específicas aplicables a diferentes tipos de respon-sabilidad.

Por otra parte, cada subsistema tiene su economía interna, y es por ello que hay pluralidad de sistemas compensatorios. No es posible pensar que el tipo de resarcimiento que se prevé para el hecho del dependiente de la gran empresa sea aplicable al hecho de la dependiente doméstica de una maestra que sale trabajar.

Percibimos una crisis de la "teoría general de la responsabilidad civil", la que para mantener la vigencia de principios conceptuales largamente elaborados, los va dotando de una abstracción cada vez mayor para comprender supuestos heterodoxos. De este modo pierden su utilidad normativa.

Creemos necesario emprender una tarea de "reconstrucción" teórica de la respon-salidad por daños ${ }^{17}$. Esta debe partir imprescindiblemente de los casos, de las responsabilidades especiales, para constatar cuánta heterogeneidad hay en ellas ${ }^{18}$. Hecha esta tarea , hay que construir a partir de esos datos los nuevos principios generales ${ }^{19}$ en una nueva "teoría general" capaz de comprender los diversos subsistemas.

\section{Los problemas decodificantes: el} derecho ambiental

Hay problemas que tienen fuerza descodificadora propia. Uno de ellos es el relativo al medio ambiente y sobre todo a los daños resarcibles.

La dificultad de identificación del responsable de la contaminación, como la presencia de casos de autores múltiples (ej. contaminación a través de residuos cloacales o de automotores), oscurece a la legitimación pasiva. El régimen de causalidad es harto complejo, no sólo por lo dicho, sino por las repercusiones mediatas de los problemas ambientales. La antijuridicidad se termina aplicando a la actividad empresaria de modo que ésta debe probar que es lícita, en términos de no contaminación, antes de instalarse, todo lo cual se contrapone con la libertad de comercio. El resarcimento a través de sumas indemnizadoras aparece cuestionado de eficacia preventiva y de destinatarios individualizados.

Se trata de problemas que demandan instituciones y herramientas propias Confluyen en ellos lo público y lo privado, lo penal y lo civil, lo administrativo y lo procesal, lándose en un cóctel innovador y heréti-

Creación de un derecho "ad boc": producción autónoma de reglas determinativas

tro dato de interés es la denominada "fuga lerecho". En el ámbito internacional se 2 a los "contratos inmunizados", que én mecanismos que neutralizan la via jul; frente al incumplimiento se ponen en n garantías y no acciones judiciales. Las Itias a primer demanda y los arbitrajes son itras claras de ello.

or otra parte, cabe observar cómo la emh ha prescindido del derecho sucesorio, tal , lo previó el legislador decimonónico para nilia. El testamento y la sucesión intestada desplazadas por la cesión de cuotas tarias, la constitución de fundaciones, las tas de ahorro,etc., que escapan al sistema cional.

a creación de redes contractuales y de unismos de sanciones, condicionan y hasupiden la acción judicial, también son un claro de este fenómeno.

il sistema codificado funcionó con reglas rminativas, de modo que los actores les sólo pueden hacer lo que surja de com$r$ tales regras. Se trata como el juego de 'ez, que debe jugarse con tales reglas; si se $\iota$ con otras reglas no será ajedrez: 20

in los fenómenos predescriptos, no se tra : meras combinaciones originales de las $s$ de derecho, sino de una "privatización" regla jurídica que secciona las partes que recen inconvenientes.

basta observar cómo se deja de lado el sho sucesorio o el de familia en la actividad resaria; cómo se desplazan las normas sozontratos típicos: o cómo se cierra la vía el "debido proceso", para tener una idea a del propósito.

Mediante estos mecanismos, las reglas rminativas, son diseñadas por las partes una de ellas.
III. Crisis de la noción jurídica de pueblo y de ciudadano

1. Crisis del Código como disciplina de los ciudadanos

El Código Civil napoleónico es la "carta jurídica del ciudadano indiferenciado 21 . El "Pueblo" tiene una unidad normativa referenciada por la Constitución (Preámbulo) y el Código (art. 1, Cód. Civil argentino). La noción de ciudadano, de raigambre francesa, surge para suprimir desigualdades provenientes del distingo entre la realeza y las clases inferiores. Esta noción abstracta sirvió para regular las relaciones privadas con una vara igualitaria.

El Código no cumple ya esa función.

El ciudadano en cuanto compra, es regulado por las leyes de consumo que difieren del Código. Si trabaja, por las leyes laborales; si comercia, por las comerciales. Si se vincula con el Estado, por el derecho administrativo.

El ciudadano es regulado en virtud de aspectos parciales: como comprador, como contribuyente, como comerciante, como usuario, como trabajador, etc., y en cada una de esas actividades enfrenta leyes especiales.

De ello se sigue que el consumo de normas especiales es mucho mayor que el de las generales. Si una empresa tiene que celebrar un contrato, recurrirá poco a la teoría general del contrato del Código Civil, y mucho más a las normas sobre impuestos, responsabilidad civil, seguros, quiebra, etcétera.

Ello lleva una crisis del concepto global y abstracto de "ciudadano" y de "Pueblo". Se nos hace difícil saber qué piensa la mayoría y cuáles son los intereses del ciudadano y del pueblo.

\section{Una ley para cada uno}

La crisis de las visiones totalizadoras ha hecho explotar todo texto unificador. Los intereses son individuales o sectoriales, perfectamente diferenciados unos de otros.

En el plano individual, el legislador se ve en problemas. Si se tuviera que tomar una decisión legislativa sobre temas sensibles, habría 
que hacer una ley para cada uno de esos individuos. Esto es lo que sucede por ejemplo con el denominado "derecho a rehusar trataminetos"; habría que hacer una ley para los testigos de Jehová y tantas otras como ideas distintas hay. De igual modo ocurre con el aborto, con la regulación de la familia, y muchos otros 22

En el plano sectorial sucede algo similar. El problema de las denominadas "leyes promocionales", que subsidian alguna actividad específica, ha producido una fragmentación de derechos y privilegios que a su vez provoca nuevas presiones sectoriales para lograr equiparación con lo obtenido por otro o superarlo. Esta lógica rompe el compromiso igualitario23.

\section{Conflitos irresolubles entre intereses igualitarios}

La existencia de intereses hiperespecializados y horizontales plantea conflictos en los que ambas partes tienen razón.

El derecho a informar que tiene el periodismo frente a la privacidad de Maradona, planteó un debate nacional en el que se vieron claramente argumentos de igual valía para ambas partes, sin que quede muy claro cuál es el "punto medio".

El desalojo de ocupantes ilegales que tienen el "derecho a una vivienda digna", vs. el "derecho de propiedad" de los titulares del dominio, ha manifestado el mismo tipo de aporías.

Los debates televisivos pueden ser ricos en argumentos contrapuestos, pero no arriba a una verdad. En el proceso judicial, donde se exponen argumentos contrapuestos, tampoco se arriba una verdad.

El proceso judicial deja de ser la averiguación de "la verdad", para transformarse en una "transacción".

\section{La feudalización del derecho}

Es interesante observar el comportamiento de un individuo mínimamente autosuficiente frente al Estado, los hiposuficientes siempre van a depender él.

Cuando existía el "Estado del bienestar", se función era redistribuir la riqueza. Todos los actores sociales querían estar vinculados al Estado porque de un modo u otro obtenían algún beneficio. El comportamiento racional era vincularse al Estado.

La función del Estado en el modelo actual es repartir costos, adjudiciar cargas. Buen ejemplo de ello, en el marco del derecho privado, es la responsabilidad civil, cuyo crecimiento se debe a una retirada del Estado en estos campos.

En este contexto, el comportamiento racional de los individuos autosuficientes es no vincularse al Estado. Las clases altas y medias viven en countrys privados donde el município tiene poco que hacer. La policía es sustituida por la guardia contratada: la escuela pública por la privada; el sistema de salud, por la medicina prepaga; el crédito estatal, por el crédito privado. Ultimamente asistimos a la peor deformación: la justicia estatal es sustituida por la justicia privada.

Este individuo no necesita del Estado, le molesta, pretende que se lo suprima, porque él está satisfecho sin necesidad de la acción pública 24 . El Estado lo molesta, le cobra impuestos, la ley le impone cargas, responsabilidades; hay que reducirla al mínimo.

No necesita del Estado porque tiene su propio feudo, y por ello se dice que asistimos a una nueva edad media 25.

El Código surge con el Estado, y éste con la nacionalidad. Este esquema fue justamente sustitutivo del feudo, e incompatible con él.

De ahí que estos fenómenos de feudalización sean descodificantes.

5. Cómo legislar lo diferente?

El Código significó una abstracción: la idea de "ciudadano" eliminaba las singularidades para tratar un concepto único al que se aplican las consecuencias jurídicas.

Frente a la heterogeneidad y a la diferencia, no tenemos conceptos similares, abarcadores 26 . a solución provisoria, que se va imendo, es dejar a cada uno la decisión indial. Se admite progresivamente que el riduo pueda decidir la subsistencia de su imonio, de su embarazo, de su vida, de la ogia genética de sus hijos, de su religión.

\section{El jurista del microsistema}

a familia se reduce, porque las personas in otras vinculaciones; los hermanos se ven con sus amigos que entre sí, los cónyuges ın más con sus compañeros de trabajo que e sí. La familia civilista también se disgrega ultiplicarse el sistema de pertenencia.

is frecuente escuchar a un civilista que le sobre el daño genético, explayarse liamente sobre temas médico - genéticos; ro que trate temas empresarios, explicar ducirse a través aspectos económicos; a n trate contratos informáticos, comenzar un desarrollo técnico-informático.

Este civilista ha tenido un contacto con otra ıcia, tal vez no muy fluido, y queda nbrado de la cantidad de cosas nuevas que :ndió y que podría aplicar al derecho priว. El segundo paso es transformarse en un recialista", y a reivindicarse como tal. El er paso será promover el tema, organizar gresos, postular sus ideas para que tegan pción legislativa.

Los congresos han dejado de ser un espacio ebate de ideas contrapuestas; los que opinan into hacen otro congreso. De este modo, usca la homogeneidad antes que el disenso, 1 de sugerir conclusiones e impacto en la unis opinio.

Los libros cumplen cada vez más una ción de "difusión" y con este propósito se eran textos, los discípulos escriben lo mo que los maestros. El fin es imponer la t.

La idea contraria y la dupla pertuban. stimos al requiem de la investigación básino se discute ni se argumenta, salvo en tradísimos cenáculos académicos.
El jurista se convierte en militante del microsistema. El Derecho civil, y los civilistas, tienden a perder imparcialidad, se transforman en militantes de verdades parciales. Lo mismo le ocurre al juez cuando tiene que resolver problemas ambientales o de consumo: él también es consumidor y está perjudicado como ser viviente.

La verdad que se expresa es subjetiva, particularizada. Se ha dicho que la izquierda "posmoderna" representa a las minorías; el derecho civil también, y con ello expresa sus límites, su carácter defensivo.

El doctrinario del Derecho vuelve, poco a poco, a ser un "exégeta", un traductor de la ley especializada.

Ello conduce a la pérdida de globalidad, de la pretensión de regular la sociedad en su conjunto, que era finalidad característica de los Códigos.

\section{El desprestigio de la ley}

1. La creación snob

El Código es una ley "Sacra"27. La proliferación de leyes es una desacralización, ya que, al abundar, las normas adquieren un carácter instrumental que las devalúan. Hay una dinámica de la creación continua de leyes e instituciones y un subsiguiente deslizamiento jerárquico 28

Todos pensamos con una supina ingenuidad, que frente a un problema, hay que sancionar una ley. Esto no ha hecho más que depreciar el poder normativo. Muchas leyes son totalmente ignoradas por los ciudadanos (tenemos como ejemplo la ley de tránsito, o la del consumidor)

Algunas leyes se contradicen con otras. Tal es el caso de la contradicción entre la responsabilidad del fabricante por productos elaborados y la que existe en la ley de residuos peligrosos $^{29}$

Leyes cuya vigencia se ignora, otras que pierden eficacia, otras que se desconocen, otras modificadas por decretos, y todas ellas creando un sistema difícil de interpretar. 
La interpretación readquiere su función fundante.

\section{La contractualización de la ley}

Se ha dicho que el contrato tiene fuerza de ley entre las partes: ahora se afirma que la ley tiene la fuerza de contrato entre las partes.

En la creación legislativa no hay un acto de soberanía estatal, sino el acuerdo previo de los grandes grupos organizados; se trata de una suerte de contrato, de acuerdo entre pocos que imponen la ley que conviene a sus intereses. En otros casos, la eficacia de la ley depende exclusivamente del consenso social que alcan$\mathrm{ce}^{30}$.

Las leyes de protección del consumidor, patentes, aborto, accidentes, son habitualmente productos de una transacción.

$\mathrm{Va}$ deteriorándose todo principio o autoridad legislativa superior cuyos mandatos están obligados a obedecer las personas por su propia naturaleza e independientemente de su aprobación.

\section{El problema de los destinatarios $y$ \\ los "tecnolenguajes"}

Es conocida aquella sugerencia kelseniana relativa a que las normas jurídicas tienen como destinatario inmediato a quienes son los encargados de aplicarlas. En su momento mereció la crítica bobbiana relativa argumentado que se hace muy difícil pensar que un reglamento sobre la circulación por carretera esté hecho para los guardias de tráfico, incluso para los jueces y no para los automovilistas.

Este problema se ha acentuado.

La ley especial suele incorporar un lenguage propio del sector que regula, técnico, un "tecnolenguaje" ${ }^{31}$, que sólo entienden individuos entrenados en ese nuevo "lunfardo" legislativo.

La norma se hace inalcanzable para el ciudadano.
4. Efectos derogatorios de la ley especial

El pensamiento codificado se basa en el silogismo: El Código es una ley general; la ley especial y la sentencia son una especificación para casos concretos. La relación entre la ley general y la especial se basa en que ambos comparten un mismo supuesto de hecho, más recortado en el segundo. El género y la especie es el modelo hermenéutico.

Como ya vimos, la lay especial puede contener principios que no son aplicación, sino derogación de la general. Algo similar sucede con el derecho jurisprudencial, en el que el juez suele "crear" derecho. Por otra parte, las leyes especiales agotan per se el supuesto de hecho, al que no se refiere habitualmente la lex generalis.

La leyes promocionales como hemos visto ut supra, contienen disposiciones que son excepciones para un grupo de ciudadanos. $\mathrm{Si}$ se aprecia de un modo general, toda norma tiene efectos distributivos específicos: tal ocurre por ejemplo con la responsabilidad limitada en materia societaria, que constituye un subsidio al riesgo empresario.

De modo similar opera el derecho "protectorio", que consagra también normas de excepción.

También hay una mutación que desarticula el esquema kelseniano acerca de la norma hipotética y la noción de sanción. Muchas leyes exceden el esquema hipotético y no prevén consecuencias sino finalidades.

La regulación basada en supuestos de hechos generalizables, es parcialmente sustituida por normas que atienden a objetivos generales.

\section{El Código como norma residual}

El hecho de contarse con un Código, dio pie para que los juristas asignaran a esos sistemas y a las normas que los constituyen una de propiedades formales que no siempre en: precisión, univocidad, cohrencia, pletitud, etcétera ${ }^{32}$.

Il Código es una norma autosuficiente, usiva, como lo señala el art. 22 del Cód. 1 , que establece que lo que no está dicho I no puede tener fuerza de ley en derecho 1. No es sólo una norma de derecho sitorio, sino que sugiere el principio ${ }^{33}$. Las :s especiales son concebidas como ongaciones del Código.

Ista idea es la que ha cambiado conforme eninos exponiendo.

-a palavra "código" comienza a escribirse minúsculas, y se la considera una ley más, eptible de sufrir tantas modificaciones ı las demás.

¿a autosuficiencia se traslada a la legislación cial. Se ha señalado que la ley especial se isforma en el derecho general de una itución, y el derecho general es una discia residual de casos no contemplados en las s especiales 34 .

\section{La crisis de la parte general del \\ Derecho Civil}

1. De la exportación de institutos a la crisis

La existencia de un Código permitió el ño de principios generales e instituciones se aplican a las relaciones privadas en ge1. Su campo de actuación no sólo se ha ndido a las leyes análogas, sino a otras leyes cluso fuera del derecho privado.

Se ha señalado que la parte general y el derecho as obligaciones del derecho civil constituyen quitectura del derecho privado.

De este modo, a través de la parte general, erecho civil exportó instituciones y técniAsí ha sucedido con la persona, el negocio dico, el contrato, la propiedad, la culpa. Este proceso de exportación ha disminuido a casi detenerse.

Advertimos más frecuentemente el śmeno contrario. Mostraremos algunos nplos.
A. La noción de persona: ha recibido el impacto de la genética, que ha puesto en crisis lo referente a la concepción intra y extrauterina; a su vez ha creado el problema del status jurídico del embrión y de los genes 35 . También la ciencia médica ha hecho temblar la idea de la muerte, con la posibilidad de mantenimiento de la vida vegetativa y el conflicto con la libertad de rechazar esos tratamientos.

Las proposiciones de la genética o de la medicina, se introducen subrepticiamente modificando las ideas o planteando nuevos problemas.

B. Los derechos personalísimos: que constituyen, tal vez, el aspecto más innovador de la parte general, no es una creación propia. Surge en los tratados y en las constituciones y de allí penetra en los códigos, condicionándolos y transformándolos ${ }^{36}$.

C. La persona jurídica: está en crisis37. La idea tradicional de constituirse en una valla que limite el riesgo empresario ha sido trastrocada por las normas impositivas, la responsabilidad societaria, la responsabilidad por el manejo de información, las normas laborales, las reglas sobre el derecho internacional privado en materia de nacionalidad. Desde ámbitos exógenos se ha condicionado este instituto de la parte general.

D. El negocio jurídico: está cuestionado. Se pregunta Galgagno ${ }^{38}$; "por qué está eclipsándose la categoria ordenante del negócio jurídico? Porque actualmente el problema no reside en construir una esfera de autonomía, contrapuesta a la soberanía del Estado...". La idea de contrato se mantiene en el derecho político como consenso originario, pero no en el sentido en que se concibió en el derecho civil: como límite a la soberanía estatal.

Ello es así porque el problema ha cambiado de coordenadas: es la "alianza planteraria entre técnica y empresa" y la "intimidad privada".

$\mathrm{El}$ agua divisoria en materia de protección la está suministrando el derecho del consumo.

E. El contrato típico: también revela poca capacidad de seducción. 
Los modelos contractuales que surgen de la tipicidad están también en un punto crítico. Su uso ha disminuido considerablemente y han proliferado los contratos atípicos. En al campo de los contratos discrecionales predominan los atípicos; en el resto los contratos de consumo. De este modo, el modelo típico que propone el legislador es poco seguido por las partes.

La mayoría de las legislaciones en materia contractual, son respuestas a la actividad empresaria, antes que un modelo jurídico que es adoptado por la actividad económica. Así se propone legislar sobre franquicia comercial, sobre contratos de distribución, sobre leasing, porque ya existen en la realidad económica con perfiles bastante nítidos.

F. La noción de derecho subjetivo: tal como se la entendió en el siglo XIX, también está mudándose. El surgimiento de grandes grupos de damnificados ha dado lugar a los intereses individuales homogéneos; la aparición de bienes colectivos ha provocado el reconocimiento de intereses difusos.

Todas estas categorías son incorporadas desde fuera de la parte general, y frecuen-temente, a través de leyes especiales.

G. El patrimonio: ha sido concebido como una emanación del sujeto, como un atributo de la personalidad. Se ha utilizado la expresión "concepción dinámica del patrimonio"39 para señalar la crisis de aquel concepto subjetivo.

En realidad es una tímida manera de señalar que el patrimonio no tiene nada que ver con la persona. El patrimonio fue, en el derecho romano, un instrumento para aliviar la situación del deudor: permitió superar el sometimiento personal para pasar a la ejecución patrimonial. En el siglo XIX, el Código diseñó al ciudadano, como individuo distinto del Estado y le dió atributos, entre los que se encontraba el nombre, la capacidad o el patrimonio. La función que cumple en ese contexto es preservar al ciudadano frente al Estado: por ello se dice que toda persona tiene un patrimonio que el mismo está sometido a su voluntad.
El patrimonio actual es un instrumento de actuación económica. Surgen asi los patrimonios separados, las sociedades unipersonales, patrimonios de afectación. E problema más importante no es el sujeto, sino la protección de los terceros. Para ello de poco sirve la noción de "atributo de la persona".

2. Mero intercambio o importación teórica?

Se podría argumentar que las influencias entre la parte general del derecho civil y su entorno han existido siempre y que sólo se trata de meras adaptaciones. Probablemente sea así en gran parte.

Sin embargo, hay aspectos centrales en los que no se trata de meras influencias, sino que el movimiento pretende sustituir los conceptos jurídicos tradicionales por otros.

Ejemplo claro de ello es la influencia que ejercen la "bioética" o el "análisis económico del derecho", al sugerir reglas de conducta con valor normativo que son receptadas por el derecho, ya sea expresamente, ya sea implícitamente mediante módulos abiertos.

\section{La crisis cultural del Derecho Civil}

\section{La crisis}

Como compaginar una Constitución anglosajona y leyes europeas?; Qué fenomenal disección se produciría si la Corte interpreta según el common law y los tribunales inferiores según el civil law? Estos interrogantes hipotéticos se asemejan a la realidad, y tienen un efecto desestructurante.

Nuestra doctrina jurídica ha sido sensible a la influencia francesa durante muchos años y hay un modelo solidarista, "jesuítico", "austero", que es bien diferente con la doctrina anglosajona 40

Si nos atenemos al canon hermenéutico de la autonomía ${ }^{41}$, y reconocemos el objeto tal como es, podemos advertir que no hay homogeneidad al respecto, sino una evidente diversidad.

\section{- La tradición anglosajona}

eremy Benthan, a través de utilitarismo, s en la Argentina del siglo XIX como un diós; el modelo de justicia para los juristas atinos era el inglés 42 . Su influencia fue srtantísima sobre Rivadavia, con quien se bía.

'edro Somellera, primer titular de la cátede Derecho Civil en la Universidad de 1os Aires ${ }^{43}$, basa la enseñanza del Derecho I en el principio de Utilidad, de Benthan. "han errado los que han creído a esta sia incapaz de demostración matemática, itica la tendencia a "nadar en el inmenso go del derecho natural", señalando que a nosotros la base de toda obligación es la dad", y el contrato es sancionado por la n virtud de la mutua utilidad que reporta partes, ya que "a la utilidad está reducido

Cau Anzoátegui, en su magnífica obra soa codificación en Argentina, observa que iso las tesis doctorales de la época eran inıciadas por el principio utilitarista, indito la de Ignacio Martínez, cuya tesis ertación sobre los contratos en general", 827 , era enteramente basada en el princite utilidad.

Manuel Belgrano, nuestro ilustre abogado bido en Salamanca, era partidario de samiento económico ${ }^{44}$. Sostenedor de zsnay, son muchísimos sus escritos rómicos y utilitaristas publicados en el reo de Comercio de Buenos Aires en allos tiempos.

Vélez Sársfield, autor del Código Civil, jió estas influencias. Fue designado proor de economía en la Universidad de nos Aires, por disposición de Rivadavia, y textos preferidos eran los de Stuart Mill. ıquellos tiempos la propiedad inmobiliaria el centro de atención de la mirada lómica. Vélez dice entonces, que fundata la creación por ley de los derechos reales a protección de la propiedad y en la sidad de evitar su desmejoramiento (nota 2502), y que siendo la locación un sistema que no mejora la cosa hay que limitar su plazo (nota art. 1505), o criticando el derecho de superficie y la enfiteusis por sus efectos económicos adversos (nota art. 2503), o al impugnar la sustitución fideicomisaria por un "obstáculo inmenso al desenvolvimiento de la riqueza” (nota art. 3724).

También tuvo importancia la escuela histórica, que revalorizaba lo nacional y el romanticismo, pero que terminó alimentando el modelo anglosajón. Ellos consideraban lo nacional, por oposición a lo español que era foráneo y valoraban la constitución de Estados Unidos en virtud de que habían creado instituciones originales.

A mediados de siglo, en 1856, Alberdi en sus conocidas "Bases", criticaba la Constitución de 1826 porque se había basado en la imitación y no en la observación, desatendiendo las necesidades económicas de la República. Decía que el derecho constitucional de la América del Sud está en oposición con su progreso material y económico, y que el Derecho Civil debía favorecer la industria y el comercio, simplificando las formas, los requisitos y el sistema probatorio en materia inmobiliaria porque ello traería "beneficio económico".

De ahí que la carta constitucional es evidentemente anglosajona, ya que exhibe una influencia norteamericana importantísima, al punto tal que se dice que ha sido su copia 45

La influencia norteamericana como modelo de organización política es innegable. Asílo señaló Gorostiaga, principal redactor de la Constitución 46

Sarmiento 47 decía no sólo que era el modelo constitucional, sino que la doctrina de lo autores norteamericanos podían ser alegados en juicio y adoptados como interpretación auténtica.

Colmo, en 1920 se quejaba de nuestros juristas que "persisten en los criterios romanista y medievales de una tradición que pesa como una lápida... Pareciera que los romanos - o Pothier hubiesen dicho la palabra definitiva..." Afirmaba que "por temperamento repudio en la ciencia cuanto no sea objetividad...", y que "el buen derecho, el derecho, ha de tener en 
cuenta los sentimientos colectivos, las enseñanzas de la economía, las prácticas en uso, las características locales, el ejemplo extraño, los mismos postulados de la filosofia, para que efectivamente sea derecho" 48

En temas importantes nuestra Corte $\mathrm{Su}$ prema ha resuelto conforme lo señala la doctrina anglosajona, chocando con los principios jurídicos tradicionales de base francesa. Por ejemplo ha aplicado la doctrina de la Corte Suprema de Estados Unidos en materia de libertad de prensa ${ }^{49}$; rescisión de contratos de concesión ${ }^{50}$, en materia de indexación 51 emergencia económica ${ }^{52}$, y muchísimos otros. Es probable que nuevos cambios en composición de la Corte, alteren esa hegemonía pero el dualismo permanecerá.

3. La transición europea

Ya Sarmiento hizo referencia al problema cultural, cuando refería el desdén con que en la Universidad de Córdoba se trataba a la obra de Benthan difundida en la Universidad de Buenos Aires, por Pedro Somellera 53 .

Pero el gran cambio se produjo con la inmigración europea, que transformó al país, cuando ya teníamos Constitución y Código Civil.

Por esta razón la legislación de derecho privado es de raigambre europea. Por ejemplo, el derecho laboral, es obra de los juristas inmigrantes, tales como Deveali, Krotoschin, y la ley 20.744 sigue al derecho europeo, y las reformas, específicamente al derecho español. El derecho comercial es fundamentalmente de inspiración italiana. El derecho civil tuvo siempre una importante influencia francesa.

4. Eclecticismo y tensión

En nuestros tiempos se vive una gran tensión cultural: la corriente anglosajona vs. la continental-europea.

El planteo no es el rechazo total o la negativa a considerar argumentos ajenos.

Este problema también existió en el siglo XIX, y Vélez Sársfield lo resolvió con practicidad y electicismo, dignos de recordar. Se valió del Código Civil francés, de Aubry y
Rau, de Demolombe, pero también de Blackstone. Utilizó obras europeas y de Estados Unidos, pero también recurrió a los latinoamericanos Freitas y a Bello.

No hubiera subsistido sin esa mixtura.

\section{Competencia legislativa en}

$$
\text { mercados integrados }
$$

En la medida en que el legislador imputa a la empresa alguna externalidad, ello le produce costos: los daños al medio ambiente, al consumidor, a los trabajadores, a los proveedores, a los otorgantes de créditos, a otros empresarios, pueden o no ser imputados a la empresa. Las empresas tienden a maximizar sus beneficios, por lo que irán donde les resulte más barato desarrollarse. Consecuentemente, la libre circulación provocará fuertes oscilaciones en el mercado en atención a las distintas regulaciones. Las empresas producirán donde la mano de obra o los servicios eléctricos sean más baratos y venderán donde los controles sean menores.

Donde haya mayor costo habrá menor actividad empresarial.

Por ello se postula que hay que corregir las denominadas "asimetrías", para evitar las distorsiones. Por ello es que normalmente se considera que en los tratados de mercado común, la armonización legislativa es mínima y sólo se limita a suprimir las diferencias que impidan o bien obstaculicen la libre circulación 54

El Tratado para la Constitución de un Mercado Común del Sur de propone la libre circulación interna de personas, bienes y servicios, y la proteción interna y la coordinación de políticas económicas. No implica sino una integración mínima que apunta a la desregulación interna y al proteccionismo externo para poder actuar en un mundo de grandes espacios económicos 55 .

Este fenómeno producirá un impacto relevante en las legislaciones nacionales, principalmente en los Códigos.

(No se trata de que serán derogados, sino de que serán ignorados en virtud de la sanción leyes especiales que se adecuen al scambio flexible. Habrá una tendencia muy a de tendencia a la baja en el proteccionismo al. Los países compiten entre sí para ver én ofrece la legislación más barata a fin de ucionar sus problemas de desarrollo $y$ empleo.

\section{La fractura del Derecho Civil}

\section{El Derecho Civil, de la persona, de la empresa y del consumidor}

Es habitual que el Código organice su maial legislativo en función de objetos de ulación: las personas, las relaciones familia, las obligaciones, los derechos reales, las esiones. También existen normas sobre iones y prescripción de derechos.

Es hảbitual que el libro sobre las personas refiera a aspectos estáticos, relativos a su entificación como sujeto de derecho: nienzo y fin de las personas, capacidad.

De esta concepción estática se pasa jgresivamente a una dinámica, a un "derecho la persona", comprensiva de la idenicación, de la identidad personal, de la egridad familiar, de los derechos persolísimos.

Se trasciende a la personà como sujeto de rechos, para comprender el diseño de lo que mos llamado una "esfera de la individualidad rsonal”. No se trata sólo de la identidad, sino establecer un margen de competencias opias de la persona, ante la cual debe tenerse toda injerencia y en establecer un ibito para su desarrollo. Esta es la probleítica que plantean el derecho a rehusar itamientos médicos, el derecho a la ivacidad, o el derecho al medio ambiente 10.

$\mathrm{Al}$ derecho de la persona física se le sumó de la persona jurídica. Ahora se le suma la rulación de los grupos, como ocurre con la ndación, el comité y la asociación en el Cóso Civil peruano. $\mathrm{El}$ grupo tiene intereses opios, y se le reconocen acciones para fenderlos.
El derecho de la persona, físicas o jurídicas, y de los grupos, asume el rol de "garantías" consagradas en defensa de los individuos, vinculando así el derecho civil con el constitucional.

El derecho patrimonial sufre una crisis en su división tradicional. La distinción decimonónica entre Derecho Civil y Comercial se diluye progresivamente, para transformarse en un derecho patrimonial unificado.

Este derecho patrimonial unificado a su vez se escinde progresivamente en varias áreas. Como hemos visto hay un microsistema de la empresa, que regula fundamentalmente la actividad económica discrecional; un derecho de protección del consumidor, que atiende a las relaciones empresa-consumidor, y un Derecho Civil, que se concentra en las relaciones entre los particulares.

El problema fundamental que se advierte es la profunda desconexión que existe entre todos estos microsistemas. Cada uno crece y se desarrolla con una gran autonomía como hemos visto.

Este fenómeno de independización se refiere al Código, ya que es evidente también que se asiste a una nueva sistematización, en la que la norma de derecho privado "ordenadora", se instala en un nivel superior, como intentaremos demostrarlo en un trabajo posterior.

Seguidamente mostraremos otra fractura que nos parece de relevancia.

\section{El acceso a los bienes y la exclusión} del derecho privado

El Código se pensó para todos los ciudadanos. Pero es claro que existe una gran cantidad de ellos que nos gozan de los beneficios que el derecho privado concede al individuo: por ele contrario, la legislación "oficial" se aplica a un sector de la comunidad. El Código Civil brasileño, por ejemplo, es poco conocido para los sesenta millones de personas que se estima que viven por debajo del nivel de pobreza; el ciudadano pobre de Estados Unidos que vive marginado en la gran ciudad, 
poco tiene que decir del commercial code, o de la consumer law.

Este es un nuevo problema que ocupa al derecho privado. El sistema económico ha ido expulsando grupos humanos importantes y la legislación no ha dado respuestas precisas para ellos.

Habrá uma legislación para los que tienen trabajo y otra, distinta, para los que no lo tienen. Una legislación para los consumidores y otra para los "sub-consumidores". Si se tiene en cuenta que un $50 \%$ del parque automotor está asegurado y el resto no tiene seguro, la reparación integral se aplica sólo al primer grupo.

El problema del "acceso" al derecho privado es central. El acceso a la propriedad, a la justicia, al consumo, al trabajo, son aspectos relevantes que ocupan y ocuparán cada vez más a nuestros civilistas.

La eficacia del derecho privado se juega en este tema.

Notas

1 WIEACKER, Franz. "Historia del Derecho privado de la Edad Moderna", ps. 197 Y sigtes., Madrid, 1957.

2 BELLO, Andrés, "Codificación del Derecho Civil", Escritos jurídicos político y universitarios, p. 59, Ed. Edeval, Valparáso, 1979.

3 MASSINI, Carlos "La desintegración del pensar jurídico enla edad moderna", Ed. Abeledo-Perrot, Buenos Aires, 1980

4 CAUMONT, Arturo-STIPANICIC, Emma, "Aplicación del concepto de poder normativo negocial fuera del área del Derecho Civil. De las obligaciones y de los contratos". Anuario de Derecho Civil Uruguayo, t. XXIII, 1993, p. 509.

5 CONDE DE CABARRUS, “Cartas sobre los obstáculos que la natureleza, la opinión y las leyes oponen a la felicidad pública", Vitoria 1808 citado por Tau Anzó́t pui, Víctor "La codificación en Argor Tau Anzoategni, Victor, "La codicacion en Argentina", Facultad de Derecho y Ciencias Sociales, Instituto de
Historia del Derecho, Ricardo Levene, 1977.

6 Una indagación de este tipo realiza IRTI, Natalino, " $\mathrm{L}$ edad de la descodificación", Ed. Bosch, Barcelona, 1992. 7 BUSNELLI, Francesco, "El Derecho Civil entre el Código y leyes especiales", Revista General de Legislación y Jurisprudencia, Ed. Reus.

8 WITTGENSTEIN, Ludwig, "Investigaciones filosóficas", trad. A. Suárez-Moulines, Ed. Crítica, Barcelona, 1988
9 Ejemplo claro de ello es la convención de Viena de 1980 sobre compraventa internacional y los proyectos de reforma al Codigo Civil desde 1987 en adelante. Sobre este tema conf.: GARRO, Alejandro-ZUPPI, Alberto, "Compraventa internacional de mercaderías", Ed. La Rocca, 1990.

10 Sobre la discusión conf. TUNC, André, "The Uniform Law on the international sale of goods: a reply to professor Nadelmann", Yale Law Journal, 1964-65.

11 Sobre este tema ver: KEMELMAJER DE CARLUCCI, Aída, "Las garantías a primera demanda", en Revista de Derecho Privado y Comunitario Rubina y Culzoni, Santa Fe, no 2, p. 93; ALEGRIA, Héctor, "Las garantías autoliquidables", rev. ídem, p. 175 .

12 PELLEGRINI GRINOVER, Ada-BENJAMIN, Antonio Herman-FINK, Daniel-BRITO FILOMENO, José Geraldo-WATANABE, Kazuo-NERY JUNIOR, Nelson-DENARI, Zelmo, "Código Brasileiro de defesa do consumidor", p. 11, Ed. For Univ., $3^{a}$ ed., 1993. En Brasil, la base constitucional surge del art. 48 que señala que debe dictarse por el Congreso un Código de Defensa del Consumidor. Cuentan los autores citados que es disposición la introdujo el lobby empresario, pensando que sería más dificultoso hacer un "código" que una ley, y que además habría garantías formales de trámite legislativo complejo.

13 BENJAMIN, Antonio, "Crimes de consumo no Código de Defesa do Consumidor", en Rev Direito do consumidor, Rev. dos Tribunais, São Paulo, $n^{\circ} 3$

14 Entre muchos ver: CAPPELLETTI, Mauro, "Dinte Mauro, Ed. Porrúa SA, México, 1993.

15 Conf.: ACOSTA ESTEVEZ, José, "La protección de 15 Conf.: ACOSTA ESTEVEZ, José, "La proteccion de
los consumidores en la comunidad europea", Prom. y

los consumidores en la comunidad
Publ. Univ. S. A. Barcelona, 1990. 16 Por ej.: STIGLITZ, Rubén, "Cláusulas abusivas en el contrato de seguro", Ed. Abeledo, Perrot, Buenos Aires, 1994.

17 Hemos profundizado en estos temas en "El sistema de a responsabilidad civil: una deuda de responsabilidad, un crédito de indemnización o una relación jurídica", LA LEY, 1993-D, 1140

18 Hemos tratado este enfoque en "La responsabilidad por daños y los accidentes de trabajo", Ed. Abeledo-Perrot, 1993

9 Hemos referido este tema en "Estudio sobre la nueva concepción normativa del riesgo creado en Derecho ar-

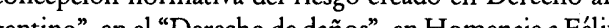
Trio Repras, Dir. Aida Ke , en Home a Félix Carlucci, coord.: Carlos Parellada, p. 339, Ed. La Rocca, Buenos Aires, 1993.

20VON WRIGHT, G., "Norma y acción”, Madrid, 1970. 21 IRTI, Natalino, "La edad ...", cit., p. 56.

22 Sobre estos temas sensibles y la dificultad inherente ellos conf. DWORKIN, Ronald, 'Life's dominnion: an argument about abortion, euthanasia, and individual freedom”, A. Knopf, New York, 1993.
IRCELLONA, Pietro-CANTARO, Antonio, "El social entre crisis y reestructuración, pub. en cho y Economía en el Estado Social”, p. 64, Ed. s, 1988.

WR AITH, John K., "La cultura de la satisfacción, mecé, 1992.

COĆ, Umberto-COLOMB, Furio-ALBERIONI, esco-SACCO, Giuseppe, "La nueva edad media", slianza, 1984

milar problema tuvieron los animales de la selva do quisieron elegir a la reina de la belleza: el león dijo lebía elegirse a la que tuviera mayor melena y mejor lo; la jirafa a la que tuviera el cuello más alto; la cebra ue tuviera más rayas; el pájaro a la que supiera volar alto. No pudieron acordar un criterio único y no , concurso.

TI, Natalino, "La societá civile-elementi per un análisi ritto privato", Ed. Giufré, 1992

IPERT Geores, en "Crisidel Diritto", 9 9, Padova, DE LOS MOZOS, José Luis, "Derecho Civil-Mé Sistemas y catog , Jos

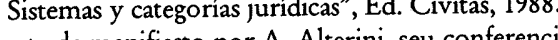
Curso de Curso de Derecho de Daños, Universidad Nacional

OLLER, Peter, "Las teorías del contrato social como lelos de justificación de las instituciones políticas", I. en KERN, Lucian-MULLER, Hans Peter, "La cia: discurso o mercado? - Los nuevos enfoques de la la contractual ista", Ed. Gedisa, Barcelona, 1992; IRTI alino, "La edad de la decodificación", p. 31 RTI, "La edad...", cit., p. 99.

INO, Carlos, "Introducción al análisis del derecho", 4, Ed. Astrea, Buenos Aires, 1992.

'IVERA, Julio, "Instituciones de Derecho Civil", t. I, 27. Ed. Abeledo-Perrot, Buenos Aires, 1992.

RTI, "La edad " cit, 33.

TI., La edad..., cit., p. 33.

CASTAN TOBEÑAS, José, "Los derechos del CASTAN TOBENAS, José, "L A $4^{\mathrm{a}}$ ed 1992 abre" ps. 118 y sigtes., Ed. Re, SAS A, $4^{2}$ ed, 1922. sobre este tema conf. DE CASTRO, Federico, "LE S MOZOS, José Luis, op. cit., p. 243.

SMOZOS, José Luis, op. cit., p. 243. GALGAGNO, Franc

n Argentina se ha difundido esta idea a través de un ayo de BUSTAMANTE ALSINA, Jorge, "La mor del deudor y la concepción dinámica del patrimonio", LA LEY, 1977-D, 481

40 Palabras de Jorge Mosset Iturraspe en su conferencia en el Congreso Internacional del Consumidor, Buenos Aires, 1993.

41 BETTI Emilio, "La interpretación de la ley y los actos jurídicos, Rev. de Derecho Privado, 1975.

42TAU ANZOATEGUI V'ctor, "La codificación en A2 TAU ANZ, DATEGU, Victor, "La codificación en Argentina Instituto de Historia del Derecho, Ricardo Levenne,
1977, p. 96 .

43 SOMELLERA, Pedro, "Principios de Derecho $\mathrm{Ci}$ vil" (curso dictado en la Universidad de Buenos Aires, en el año 1824, Instituto de Historia del Derecho Argentino, Buenos Aires, 1939)

44 BELGRANO, Manuel, "Escritos económicos", Hispamerica, 1988

45 Ver SAMPAY, Arturo, "Las Constituciones de Argentina”, 1810-1972, p. 63, Eut. I, 1975.

46 VANOSSI, Jorge, "La influencia de José Benjamín Gorostiaga en la Constitución Argentina”, p. 25, Buenos Aires, 1975.

47 "Comentarios a la Constitución de la Confederación Argentina".

48 COLMO, "Tratado teórico práctico de las Obligaciones en el Derecho Civil argentino-De las obligaciones en general”, Ed. Jesús Menéndez, Prólogo, Buenos Aires, 1920

49 Sobre el problema del derecho americano y las decisiones de la Corte en materia de libertad de prensa, ver PIZARRO, Daniel, Daños derivados de la publicación de una sentencia por la prensa", JA del 29.12.93; y SAUX, Edgardo, "Libertad de prensa: un perceptible reasunción de criterios aperturistas en la doctrina judicial de la Corte Suprema de Justicia de la Nación”, JA del 27.4.94.

50 Automotores Saavedra c. Fiat Argentina S. A., LA LEY, 1989-B, 4.

51 "YPF c. Corrientes", LA LEY, 1992-B, 216.

52 "Peralta, Luis c. Gobierno nacional", LA LEY, 1991. C. 159

53 SARMIENTO, Faustino, "Facundo", 78.

54 CATALANO, Nicola "Manual de Derecho de las Comunidades Europeas", 1966.

55 Conf considerandos y art. 1, según ley 23.981. 